\title{
The Effect of Assortment Changes on Consideration Set Formation
}

\author{
Wirawan Dony Dahana \\ Osaka University \\ E-Mail: dony@econ.osaka-u.ac.jp
}

\begin{abstract}
Product assortment is one of the most important determinants of store performance. Past studies have shown that a reduction in the number of items can alter sales. This paper examines the impact of assortment changes on the formation of the consumer consideration set when an item is delisted as well as when a new item is introduced. We employed a choice model that incorporates the consideration effect based on the theory of search and applied this model to scanner data in the toothpaste category. We found that when an item was eliminated, its former buyers adjusted their consideration set by replacing the delisted item with items sharing common key attributes with it, followed by promoted and low-priced items. Furthermore, the consideration set was affected by the introduction of a new item in a way that the newly introduced item drew a large share of consideration from items that were similar in terms of product attributes.
\end{abstract}

Keywords: Product Assortment, Consideration Set, Brand Choice

\section{INTRODUCTION}

Determining optimal product assortment is an important issue from a managerial standpoint. Retailers periodically reevaluate the width and the depth of the product variety they carry to meet consumer needs, enhance shopping convenience, and ultimately increase sales or profit. In order to achieve these purposes, retailers might undertake assortment reduction by delisting low-traffic items or introducing new items that are more promising.

The implementation of product assortment strategies, however, has to be planned and conducted carefully, because it is believed that it affects consumer perceptions 
and behavior. Using various methods such as laboratory and natural experiments, researchers have reported that a change in the width or the depth of product assortment can influence consumer perceptions about the variety of products (Broniarczyk, Hoyer and McAlister 1998), store choice (Briesch, Chintagunta and Fox 2009), sales (Boatwright and Nunes 2001), and customer retention (Borle and colleagues 2005).

In this paper, we examine what effects a change in product assortment has on the consumer consideration set. We have focused on how consumers would change their consideration sets when they know that an item is no longer on the shelf or a new item has been introduced at the store they visited. To the best of our knowledge, there is very limited research that addresses this question. However, we argue that the present research can provide considerable contributions to the literature. In addition, a better understanding of how consumers adjust their consideration sets as a reaction to product variety changes can provide useful insights for retailers and manufacturers.

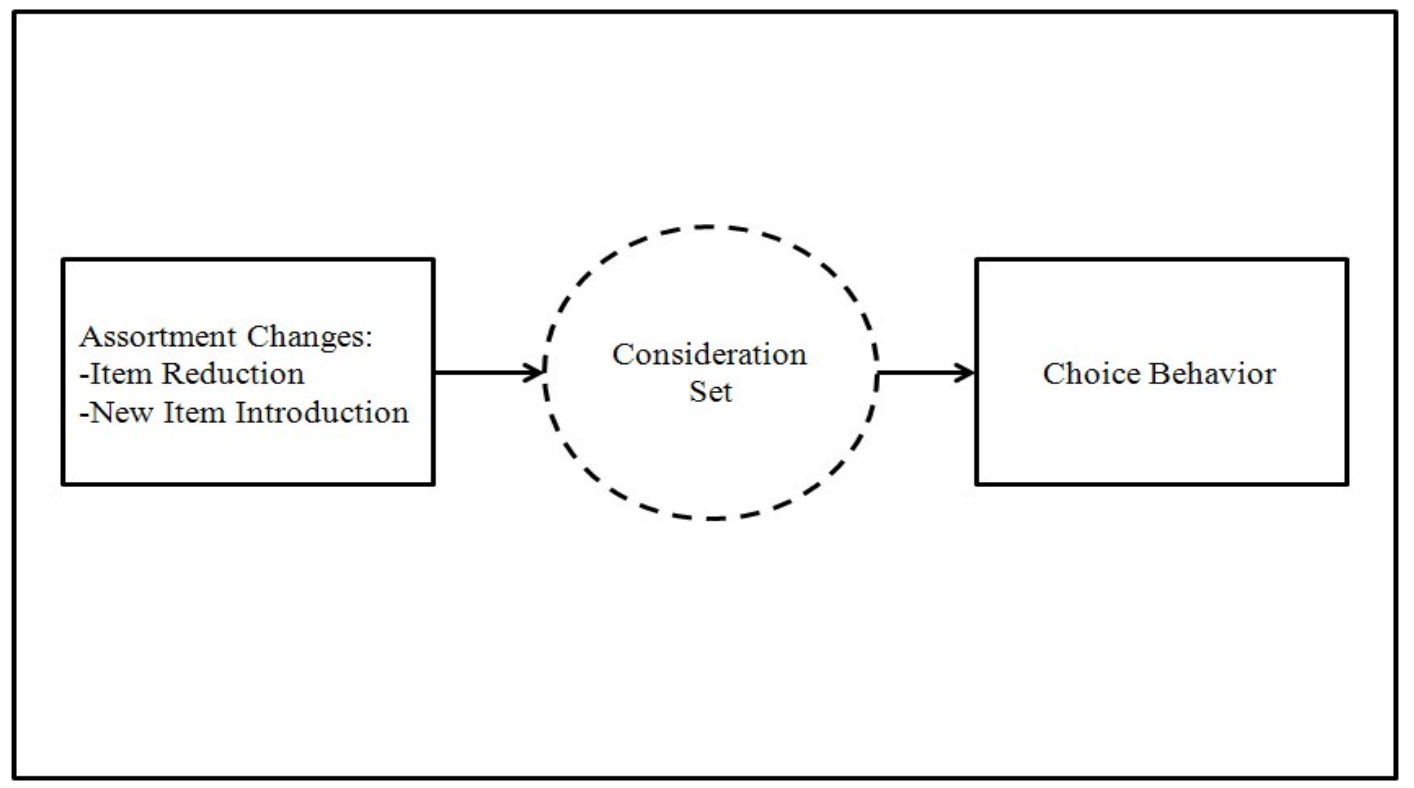

Figure 1 Assortment effects on consideration set formation and choice

The basic idea behind current, existing research is illustrated in Figure 1. When consumers recognize that there has been a change in product assortment, they adapt their consideration sets to this new environment by adjusting its contents. This is done on the basis of preferences toward items in order to maintain the quality of choice. Consequently, a change in consideration sets could lead to a change in choice 
outcomes. What we want to do is to capture and analyze the dynamics of a consideration set as a result of assortment changes. However, the task is challenging because in general it is difficult, if not impossible, to directly observe a consumer consideration set. In the data we analyze, we can observe only the change in product assortment and choice outcomes.

To overcome this problem, we utilized a two-stage choice model in which consumers are assumed to trade off between utility and processing costs when constructing their consideration sets from which the choice is made (Roberts and Lattin 1991). The formation of a consideration set is carried out through a sequential search in which consumers inspect each item for consideration in the order of its utility. We employed the Bayesian modeling framework and defined the posterior distributions of model parameters. An application of the MCMC method allows us to make inferences about the contents of consideration sets at the individual level and to track changes over time associated with assortment changes.

The results show that when an item was delisted from the shelf, the composition of the consideration set of its former buyer was significantly altered by the reduction. Recognizing that the item they usually buy is no longer available, these consumers seem to consider buying other items that share common attributes with the delisted one, followed by items that are heavily promoted and low-priced. On the other hand, non-buyers are likely not affected by the change in assortment. When an item was introduced in target stores, consumers who buy products that have attributes similar to the new one take this item into consideration.

The remainder of this article is organized as follows. In section 2, we review previous works related to assortment effects and the consideration set. A two-stage brand choice model that can accommodate the effect of assortment changes on consideration set formation is discussed in detail in section 3. We introduce the data to which we apply the model in section 4. Estimation results and discussions will be provided in section 5. Finally, section 6 concludes the study.

\section{LITERATURE REVIEW}

The effect of product assortment on retail performance has gained considerable attention in the field of marketing. In the literature, it is reported that perceptions of product variety determine consumers' attitudes toward store and store choice, ranked immediately behind location and price (Arnold et al. 1983; Craig et al. 1984; Louviere and Gaeth 1987). The main focus in previous studies has been the sales impact of assortment reductions (e.g. Drèze, Hoch and Purk1994; Boatwright and Nunes 2001; 
Borle and colleagues 2005).

The results, however, varied across studies and product categories. The positives sales effects of assortment reductions are reported in a study by Drèze, Hoch and Purk (1994) which examined a 10 percent item reduction in eight categories. Boatwright and Nunes (2001) found that to some extent, item reductions lead to sales increases but can have negative effects as the number of delisted items increases. Mixed results were also reported in a study by the Food Marketing Institute (1993) which examined the sales impact of item reductions in six product categories.

Despite contradictory results, there is sufficient evidence to show that the effects of item reductions varied between buyers and non-buyers of delisted items (Broniarczyk, Hoyer and McAlister 1998; Sloot, Fook and Verhoef 2006). While non-buyers may not be affected by the reductions, former buyers of delisted items often adjust their perceptions about product variety and thus change buying behavior after recognizing that a favorite item is no longer available. Sloot, Fook and Verhoef (2006) posit that item reductions can lead former buyers to switch to other items in the category, switch stores, or postpone the timing of their purchase.

Broniarczyk, Hoyer and McAlister (1998) argue that non-buyers of delisted items will not be substantially affected by such a reduction because they might not take it into consideration when making a purchase. Therefore, the reduction will go unnoticed by these consumers, and no significant change in their purchase behavior will result. On the other hand, former buyers will immediately notice the absence of their favorite item because it has a great probability to enter the consideration sets of the consumers. In the absence of their favorite item, there will be a change in consumers' perceived market structure (Urban, Johnson and Hausser 1984). In such a situation, consumers will need to reevaluate the attractiveness of available alternatives based on the attributes and attribute levels in order to form product preferences (Chernev 2003).

The question now is how consumers adjust their consideration set given the fact that their favorite item has been delisted. One can expect that consumers will reconstruct their consideration set in some way to maintain the quality of choice they have achieved so far. This can be done by using the current consideration set minus the delisted one or forming a new set that contains some items that share common attributes with the delisted one. This study is aimed at answering the above question by making an inference about a consideration set and tracking its dynamics with respect to the changes in product assortment. Note that we also examine the effects of new item introduction on a consideration set in addition to item reduction. 
The concept and the existence of consideration sets have received great support in the area of consumer research (Hauser and Wernerfelt 1990; Shocker and colleagues 1991). Previous studies have explored how consumers form consideration sets and what factors influence the formation process. Hauser and Wernerfelt (1990) argued that whether or not a product is considered by a consumer is dependent upon consumer preference. Swait and Erdem (2004) suggested that brand credibility is one of the important determinants of consideration set formation. Marketing mix variables such as in-store displays and advertising stock have also proved influential in the inclusion of a product in a consideration set (Allenby and Ginter 1995; Terui, Ban and Allenby 2011). As mentioned above, we argue that a change in product assortment has potential effects on consideration set formation. However, this issue has not been addressed sufficiently in past studies, and therefore, present research can provide valuable contributions to existing literature.

Accounting for the concept of a consideration set in the brand choice model is challenging because of its latent construct. Roberts and Lattin (1991) proposed a choice model that involves the formation of a consideration set. The approach is based on the comparison of the marginal expected benefits of including an additional brand in the consideration set with its associated costs. However, the model requires survey data of consideration set composition, which is generally not available in scanner data. Andrews and Srinivasan (1995) proposed a two-stage choice model that is applicable to scanner panel data. In their model, the inclusion probability of each brand in a consideration set is assigned and assumed to be a function of marketing mix variables. The model, however, gives rise to computation problems when we deal with a large number of items, which makes it difficult to apply. ${ }^{1}$

The approach we use in this research is that of Roberts and Lattin (1991). However, unlike Roberts and Lattin, we employed a Bayesian framework to attain posterior distributions of the parameters of interest (i.e. consideration costs and utility function). Using the MCMC method, we estimate model parameters by drawing random numbers from the posterior distributions. In so doing, we are able to infer individual-level consideration sets that consumers form at every purchase occasion from scanner data.

\section{THE MODEL}

We begin with utility function, which represents consumer preference toward items that are available on the market. We assume that the utility of consumer $i$ for

${ }^{1}$ Manrai and Andrews (1998) provide a comprehensive review for models of this class. 
item $j$ at purchase occasion $t$ is dependent upon intrinsic preference for the item, price, and item loyalty, which is represented by:

$$
u_{i j t}=\alpha_{i j}+\beta_{i 1} P_{i j t}+\beta_{i 2} G L_{i j t}+\varepsilon_{i j t}
$$

where $\alpha_{i j}$ is consumer $i$ intrinsic preference toward item $j, P_{i j t}$ is the price of item $j$ encountered at the occasion, and $G L_{i j t}$ is consumer item loyalty. The loyalty variable has been used widely in marketing literature to capture the consumer state dependent and is defined as $G L_{i j t}=\gamma G L_{i j(t-1)}+(1-\gamma) I_{j h(t-1)}$ (Guadagni and Little 1983), where $I_{j h(t-1)}$ is an indicator function taking value 1 if the consumer purchased item $j$ on a previous occasion and 0 otherwise. Finally, $\varepsilon_{i j t}$ represents the stochastic error component in utility, which is assumed independently and identically distributed according to extreme value distribution. To account for the effects of product attributes on choice, we model $\alpha_{i j}$ as a function of product attributes (levels) and defined as $\alpha_{i j}=a_{i j}+b_{i 1} D_{1}+\cdots+b_{i m} D_{m}$ (Elrod and Keane 1995), where $a_{i j}$ is consumer utility for item $j$ unique attribute and $D_{k}$ is a dummy variable which is 1 if item $j$ possesses the $k$-th attribute level and 0 otherwise.

Following the notion of brand categorization, we assume that consumer choice is made not from the entire set of available items, but, rather, from a smaller set of items (consideration set). This implies that any item that does not belong to the consideration set will not be chosen (i.e. its choice probability is 0 ). Let $C_{i t}$ denote consumer $i$ 's consideration set at occasion $t$ and $v_{i j t}$ denote the deterministic part of $u_{i j t}$, which is then conditional on item $j$ being in $C_{i t}$, the probability of choosing the item is given by the following multinomial logit model (McFadden 1973).

(2) $P_{i t}(j)=\frac{\exp \left(v_{i j t}\right)}{\sum_{k \in C_{i t}} \exp \left(v_{i k t}\right)}$

The criterion for an item to enter a consumer's consideration set is based on a tradeoff between utility and mental storage and processing costs (Roberts and Lattin 1991). As shown by Ben-Akiva and Lerman (1985), under the assumption of the logit model, the value of making a choice from consideration set $C_{i t}$ can be thought of as the expected maximum utility of a choice from the set. The value is represented by: 
(3) $V\left(C_{i t}\right)=\ln \left(\sum_{k \in C_{i t}} \exp \left(v_{i k t}\right)\right)$.

For an item to enter the consideration set, the incremental benefit gained from including it must be greater than the marginal cost a consumer bears for making a decision from a larger set. In other words, given a set of items having been in $\mathrm{C}_{\mathrm{it}}$, a consumer decision as to whether to take additional item $\mathrm{j}$ into consideration or not depends on the marginal value of choice and marginal cost associated with the inclusion. Formally, the condition for item $\mathrm{j}$ to be included in the consideration set can be expressed as:

$$
V\left(C_{i t} \cup j\right)-V\left(C_{i t}\right)>c_{i}
$$

where $c_{i}$ denotes marginal cost consumer $\mathrm{i}$ bears. ${ }^{2}$ As pointed out by Roberts and Lattin (1991), the costs of considering an item include many aspects, such as search costs, thinking costs, mental processing and storage costs, etc. Because the costs of considering an item cannot be directly observed from our data, we employed the Bayesian inference framework and estimated its value from the data using the MCMC method with Metropolis-Hastings algorithm. ${ }^{3}$ Without loss of generality, we assume that consumers apply a sequential search in the consideration of set formation. This means that the item with the highest utility is inspected first, followed by the second highest utility item, and so on (Weitzman 1979).

The main objective of this study is to examine how consideration sets are influenced by assortment changes. The model framework discussed above allows us to make inferences about the contents of a consideration set at each purchase occasion. In so doing, we can analyze how the composition of a consideration set may be affected when a change in product assortment takes place.

\footnotetext{
${ }^{2}$ Note that we assume that marginal cost is constant with respect to the number of items in a consideration set. This implies a linear cost function. One can, alternatively, impose other specifications such as increasing marginal cost, in which cost increases exponentially as the number of items increases.

${ }^{3}$ We treated marginal cost as a threshold parameter and estimated its value using a method proposed by Terui and Dahana (2006) and Terui, Ban and Allenby (2011). Given the value of marginal cost, a consideration set is defined, and choice coefficients can be estimated using an $\mathrm{M}-\mathrm{H}$ algorithm.
} 


\section{DATA}

We applied the model described in the previous section to loyalty-card data provided by Consumer Communications Ltd, a research company in Japan. Data on household purchases in four drug stores belonging to a large retail chain were available for two years, beginning from August 1, 2008. We chose the toothpaste category, in which assortment changes actually took place. Fourteen SKUs, which accounted for 39 percent of quantity share in the target stores, were selected for analysis. Average prices ranged from 74 to 1,234 yen.

Category purchases were made by customers who participated in the store loyalty program. Each of them has a loyalty card, which is to be shown to a store clerk when making payment. We selected those who made at least ten purchases during the data period. This resulted in 672 customers, of which 89 percent are female and approximately 50 percent are between 40 and 60 years of age. Most of those selected bought two to five different items during the data period.

Table1 Descriptive Statistics for Data

\begin{tabular}{ccc|ccc}
\hline Items & $\begin{array}{c}\text { Average } \\
\text { Price }\end{array}$ & $\begin{array}{c}\text { Quantity } \\
\text { Share }\end{array}$ & Items & $\begin{array}{c}\text { Average } \\
\text { Price }\end{array}$ & $\begin{array}{c}\text { Quantity } \\
\text { Share }\end{array}$ \\
\hline A & 122 & $4.23 \%$ & $\mathrm{H}$ & 101 & $1.33 \%$ \\
B & 752 & $1.34 \%$ & $\mathrm{I}$ & 220 & $9.77 \%$ \\
$\mathrm{C}$ & 74 & $5.02 \%$ & $\mathrm{~J}$ & 138 & $1.78 \%$ \\
$\mathrm{D}$ & 176 & $4.17 \%$ & $\mathrm{~K}$ & 148 & $2.19 \%$ \\
E & 303 & $0.97 \%$ & $\mathrm{~L}$ & 343 & $0.88 \%$ \\
F & 272 & $0.79 \%$ & $\mathrm{M}$ & 1,234 & $1.81 \%$ \\
G & 257 & $1.35 \%$ & $\mathrm{~N}$ & 120 & $3.44 \%$ \\
\hline
\end{tabular}

Table 1 provides descriptive information about the data. Actual brand names are masked to preserve confidentiality. The largest item is item I, which accounts for 9.77 percent of the total quantity share. We didn't have marketing mix variables such as in-store displays and feature adverting, except price. Therefore, we could only know whether an item was on promotion or not based on the information obtained from its price. For the item loyalty variable, we followed Guadagni and Little (1983) by setting its initial value at 0.75 for the chosen item and $0.25 /(k-1)$ for other items in a consideration set the size of $k$. 
Since we wanted to explore the role of SKU attributes in the formation of a consideration set, we sought to determine what would be treated as a SKU attribute to use in our analysis. It is suggested that a SKU attribute must be consumer recognizable and objective and must apply to every item in the category (Fader and Hardie 1996). Considering the characteristics of the toothpaste category as a medical product, we selected efficacy as the key attribute. Based on marketing communication activities carried out by each manufacturer, we listed the efficacies along with the items that possessed the attribute level in Table 2. Note that although some items are marketed as having more than one efficacy, we classified each item based on the efficacy for which it is most appealing. Because items that have cavity prevention and periodontal disease prevention attribute levels occupied a large portion of market share, we included only three attribute levels in the model: cavity prevention, periodontal disease prevention, and others.

Table 2 The Key Attribute of Toothpaste Category

\begin{tabular}{ll}
\hline \multicolumn{1}{c}{ Efficacies } & \multicolumn{1}{c}{ Items } \\
\hline Cavity prevention & A, C, D, H, K \\
Periodontal disease prevention & B, F, G, J, L, M \\
Whitening & I, N \\
Bad breath treatment & E \\
\hline
\end{tabular}

One of the items, item F, was delisted from the shelf at the end of the fourth month of the data period because its manufacturer conducted product renewal. For the next four months, the delisted SKU had been absent in the target stores before coming back with some changes to its attributes. We treated the new item as a different item from its old version and denoted it as item G. The delisted item F was purchased by 27 households. During the absence of the item, its former buyers kept making purchases in the category at one of the target stores. Most of them switched to items that share common efficacy attributes with $\mathrm{F}$ or to items that are heavily promoted. After the introduction of item $\mathrm{G}$, these households switched from those items to item G.

Figure 2 describes how choice shares of the items changed with respect to assortment changes. Accordingly, Figure 2 displays the choice shares during three different periods: the initial period before the assortment change took place, the period after $\mathrm{F}$ was delisted, and the period after $\mathrm{G}$ was introduced. We split choice data into that of former buyers of item $\mathrm{F}$ and non-buyers to see how they differ in reacting to the change in assortment. The upper panel shows the changes in choice shares of item 
F among former buyers. As we can see, initially item F made up 33 percent of the quantity bought by these households. When the item was delisted, most of the households switched to item L, which offers the same efficacy (periodontal disease prevention) as item $\mathrm{F}$. The share of item $\mathrm{K}$ is also observed to increase, and we recognize that this happened due to heavy promotions implemented for the item during the period. When item $G$ was introduced, most of these customers switched to this brand-new item, resulting in a significant decrease in almost other items. On the contrary, we don't see any significant change in choice shares for non-buyers (lower panel). This is consistent with the results reported in previous studies (e.g. Sloot, Fook and Verhoef 2006).

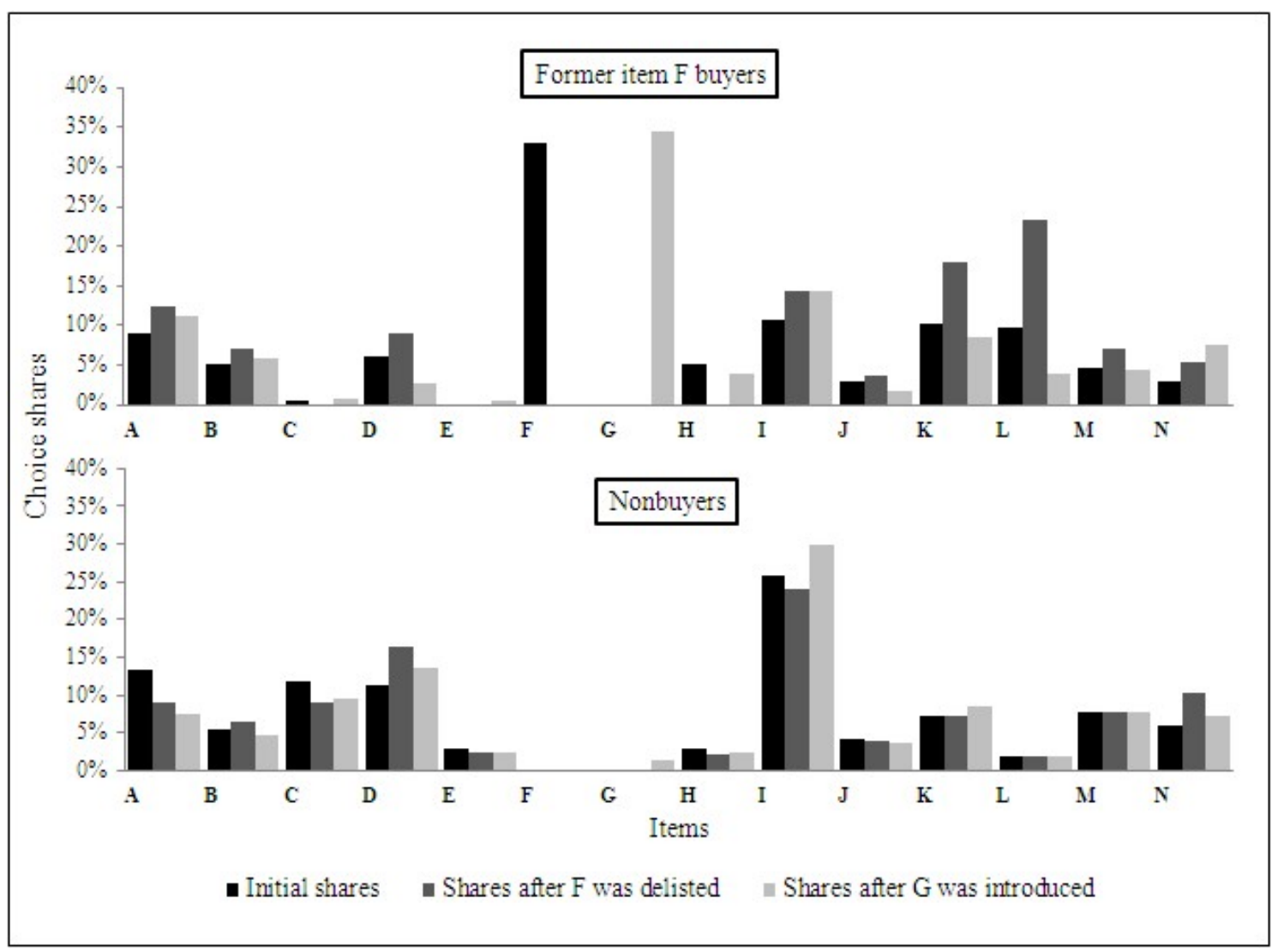

Figure 2 Changes in Choice Shares

\section{RESULTS AND DISCUSSION}

Parameter estimates of the two-stage logit model are displayed in Table 3. Note that the estimates of unique attribute parameters are not displayed for the sake of 
brevity. The table shows that all parameter estimates have expected signs. Because all parameters were estimated at the individual level, we used the 95 percent HPD region to test the validity of the variables for each individual customer. For each variable, we displayed the number of customers whose coefficients are significant (the HPD regions did not include 0 ) in the rightmost column of the table. On the average, cavity prevention is the most preferred attribute. However, this may not the case for former buyers of item F. We also find that for most households, item loyalty variables have a significantly positive effect on choice, indicating state dependence.

We estimated individual-level consideration sets at each purchase occasion. We then pooled the results to calculate the consideration share for each item, defined as the number of times that the item was considered divided by the total number of purchases, which indicates its relative frequency of entering the consideration set. The results for item $\mathrm{F}$ buyers and non-buyers are displayed in Figure 3. In the case of item F buyers, the consideration share for item $\mathrm{L}$ increased markedly, from 16.59 percent to 34.29 percent. As we have seen in Figure 2, this item is a close competitor of the delisted item. Item F buyers might have seen this item as the closest substitute for their favorite one and placed it as a high priority item in their consideration set.

Table 3 Parameter Estimates of Logit Model

\begin{tabular}{lccc}
\hline \multicolumn{1}{c}{ Coefficients } & $\begin{array}{c}\text { Posterior } \\
\text { mean }\end{array}$ & $\begin{array}{c}\text { Posterior } \\
\text { STD }\end{array}$ & $\begin{array}{c}\text { \# of significant } \\
\text { coefficients }\end{array}$ \\
\hline Cavity prevention & 3.51 & 1.48 & 391 \\
Periodontal disease & 1.76 & 0.83 & 243 \\
prevention & & & \\
Other attributes & 0.18 & 0.95 & 336 \\
Price & -5.27 & 1.79 & 624 \\
Item loyalty & 6.41 & 2.96 & 613 \\
\hline
\end{tabular}

Although it was not as prominent as item L, we also observed an increase in shares for items B and J, which share a common efficacy attribute with item F. However, this was not the case for item M, although the item has the same efficacy as item $\mathrm{F}$. This is perhaps because item $\mathrm{M}$ is priced far higher than the market average and is targeted to a different particular segment. Significant increases were also observed for items $\mathrm{H}$ and $\mathrm{K}$. As already mentioned, item $\mathrm{K}$ was heavily price-promoted during the period, which was thought to lead some customers to see the item as attractive and consider buying it. In fact, as shown in Figure 2, the choice 
share of item $\mathrm{K}$ increased by about 6 percent during that period. In the case of item $\mathrm{H}$, we surmised that the increase was due to the existence of risk-averse households. Recognizing that their favorite item was no longer available, these consumers adjusted their consideration set by including a low-priced item to avoid monetary risks associated with the purchase.

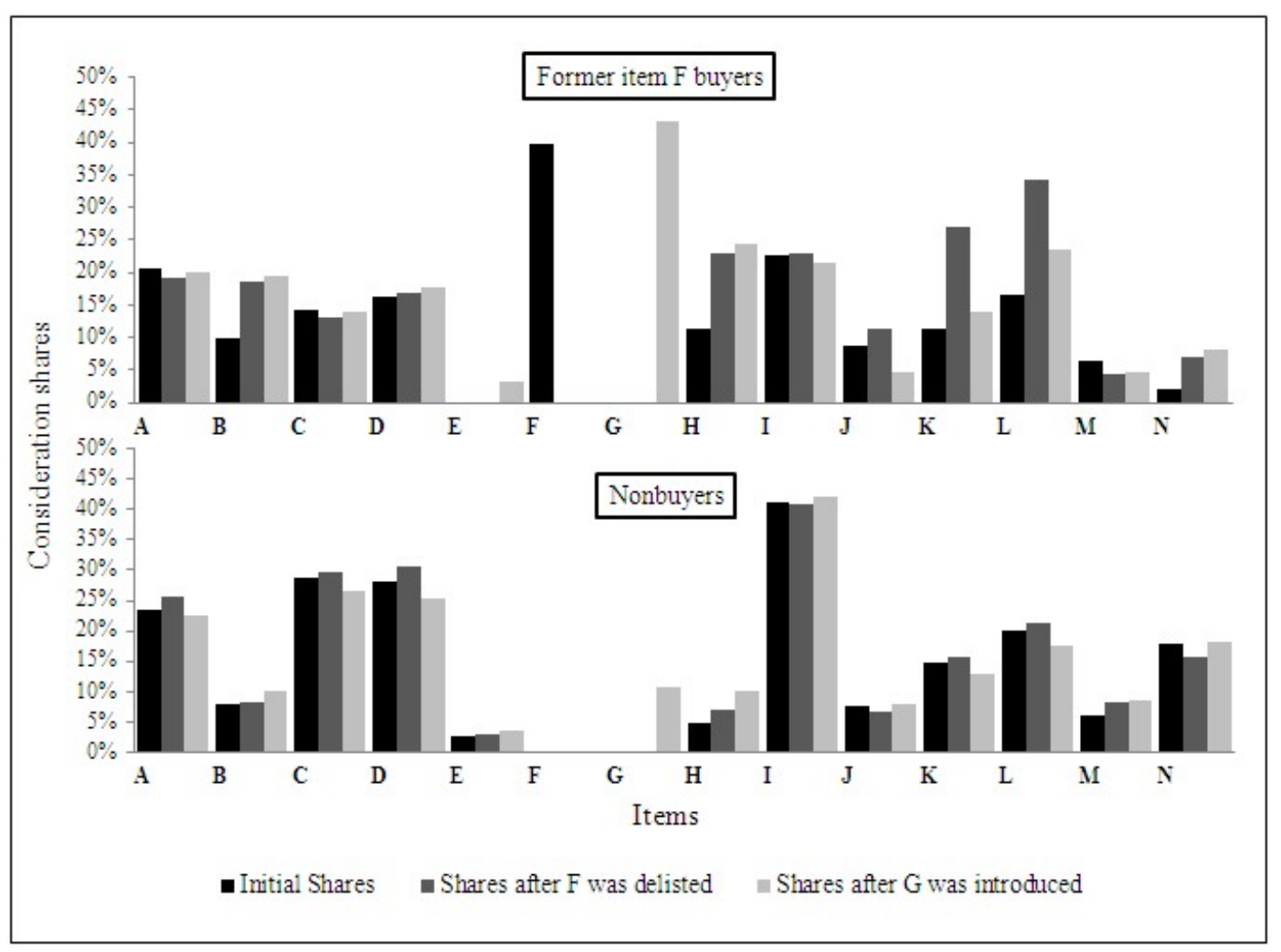

Figure 3 Changes in Consideration Shares

Now let's see what happened after item G was added to the stores' shelves. Former buyers of item $\mathrm{F}$ took the new item into consideration as frequently as they did item F. Consequently, the consideration shares of items $\mathrm{K}$ and $\mathrm{L}$, which experienced significant increases in the absence of item F, dropped by about 13 percent and 11 percent, respectively. However, their shares are still greater than they were in the initial period. The results for items $\mathrm{B}$ and $\mathrm{H}$ are interesting, because the shares remained almost unchanged after the introduction of item G. Our interpretation concerning these results is that when item $\mathrm{F}$ was delisted, its former buyers replaced the delisted item with the other items mentioned above. Some of these consumers may have found that the items were worth considering and continued including them in 
their consideration sets, even after the more attractive item $\mathrm{G}$ was introduced.

The results for non-buyers of item $\mathrm{F}$ are similar to those in choice shares. That is, there is no significant change in a consideration set with respect to assortment changes. As pointed out by Broniarczyk, Hoyer and McAlister (1998), these consumers might not even be aware that the item has been deleted. Consequently, the formation of a consideration set remains unchanged.

\section{CONCLUDING REMARKS}

This study examined how consumers changed their consideration sets when an item was delisted and a new item was introduced. Our empirical implication, as far as our data set is concerned, reveals that the effects of assortment changes varied between former buyers and non-buyers and accordingly supports previous findings. When an item is delisted, its former buyers will adjust their consideration sets by including those items which share a common attribute with the eliminated item, those items which are heavily promoted, and those items which are low-priced. The introduction of a new item affects current consideration shares in a sense that the new item will draw a large portion of consumer consideration from its close competitors. In the case of non-buyers, no significant effects were revealed.

We believe that our findings could be useful for marketers in charge of assortment or product line management. For example, when a retailer is about to reduce some items in order to save costs, he/she can anticipate what the customers would consider buying when they find that their favorite item is not available. Similarly, he/she can also anticipate how consideration sets of customers would change if some item is added to the current assortment. We argue that this ability can provide valuable information relevant to effective promotional activities. However, our findings may not be immediately generalizable to other categories. As shown in the previous studies, since assortment effects varied across categories, cross-categorical research is thus called for.

\section{REFERENCES}

Allenby, G., and J. L. Ginter (1995). The effects of in-store displays and feature advertising on consideration sets. International Journal of Research in Marketing, 12(1), 67-80. http://dx.doi.org/10.1016/0167-8116(95)00006-N

Andrews, R. L., and T. C. Srinivasan (1995). Studying consideration effects in empirical choice model using scanner panel data. Journal of Marketing Research, 32(1), 30-41. http://dx.doi.org/10.2307/3152108 
Arnold, S. J., H. O. Tae, and J. T. Douglas (1983). Determining attributes in retail patronage: seasonal, temporal, regional, and international comparisons. Journal of Marketing Research, 20(2), 149-157. http://dx.doi.org/10.2307/3151681

Ben-Akiva, M., and S. R. Lerman (1985). Discrete Choice Analysis, Cambridge, MA: MIT Press.

Boatwright, P., and J. C. Nunes (2001). Reducing assortment: an attribute-based $\begin{array}{llll}\text { approach. Journal of } & \text { 50-63. }\end{array}$ http://dx.doi.org/10.1509/jmkg.65.3.50.18330

Borle, S., P. Boatwright, J. B. Kadane, J. C. Nunes, and G. Shmueli (2005). The effect of product assortment changes on customer retention. Marketing Science, 24(4), 616-622. http://dx.doi.org/10.1287/mksc.1050.0121

Briesch, R. A., P. K. Chintagunta, and E. J. Fox (2009). How does assortment affect grocery store choice?. Journal of Marketing Research, 46(2), 176-189. http://dx.doi.org/10.1509/jmkr.46.2.176

Broniarczyk, S. M., and W. D. Hoyer, and L. McAlister (1998). Consumer's perceptions of assortment offered in a grocery category: the impact of item reduction. Journal of Marketing Research, 35, 166-176.

Chernev, A. (2003). Product assortment and individual decision processes. Journal of Personality and Social Psychology, 85(1), 151-162. http://dx.doi.org/10.1037/0022-3514.85.1.151

Craig, C. S., G. Avijit, and S. McLafferty (1984). Models of retail location process: a review. Journal of Retailing, 60, 5-26.

Drèze, X., S. J. Hoch, and M. E. Purk (1994). Shelf management and space elasticity. Journal of Retailing, 301-326. http://dx.doi.org/10.1016/0022-4359(94)90002-7

Elrod, T., and M. P. Keane (1995). A factor-analytic model for representing the market structure in panel data. Journal of Marketing Research, 32(1), 1-16. http://dx.doi.org/10.2307/3152106

Erdem, T., and J. Swait (2004). Brand credibility, brand consideration, and choice. Journal of Consumer Research, 31(1), 191-198. http://dx.doi.org/10.1086/383434

Fader, P. S., and B. G. S. Hardie (1996). Modeling consumer choice among SKUs. $\begin{array}{llll}\text { Journal of } \quad \text { Marketing } & \text { Research, }\end{array}$ http://dx.doi.org/10.2307/3152215

Food Marketing Institute (1993). Variety or Duplication: A Process to Know Where You Stand. Washington, DC: Food Marketing Institute.

Guadagni, P. M., and J. D. C. Little (1983). A logit model of brand choice calibrated 
on scanner data. Marketing Science, 2(3), 203-238. http://dx.doi.org/10.1287/mksc.2.3.203

Hauser, J. R., and B. Wernerfelt (1990). An evaluation cost model of consideration set. Journal of Consumer Research, 16(4), 393-408. http://dx.doi.org/10.1086/209225

Louviere, J. J., and G. J. Gaeth (1987). Decomposing the determinants of retail facility choice using the method of hierarchical information integration: a supermarket illustration. Journal of Retailing, 63, 25-48.

Manrai, A. K., and R. L. Andrews (1998). Two-stage discrete choice models for scanner panel data: an assessment of process and assumptions. European Journal of Operational Research, 111(2), 193-215. http://dx.doi.org/10.1016/S0377-2217(98)00145-3

McFadden, D. (1973). Conditional logit analysis of qualitative choice behavior. in Frontiers in Econometrics, Philip Zambreka, ed. New York: Academic Press.

Roberts, J. H., and J. M. Lattin (1991), Development and testing of a model of consideration set composition. Journal of Marketing Research, 28(4), 429-440. http://dx.doi.org/10.2307/3172783

Shocker, A. D., M. Ben-Akiva, B. Boccara, and P. Nedungadi (1991). Consideration set influences on consumer decision-making and choice: issues, models, and suggestion. Marketing Letters, 2(3), 181-197. http://dx.doi.org/10.1007/BF02404071

Sloot, L. M., D. Fok, and P. C. Verhoef (2006). The short- and long-term impact of an assortment reduction on category sales. Journal of Marketing Research, 43(4), 536-548. http://dx.doi.org/10.1509/jmkr.43.4.536

Terui, N., M. Ban, and G. M. Allenby (2011). The effect of media advertising on brand consideration and choice, Marketing Science. 30(1), 74-91. Retrieved from http://mktsci.journal.informs.org/content/30/1/74.short

Terui, N., and W. D. Dahana (2006). Estimating Heterogeneous Price Thresholds, Marketing Science, 25(4), 384-391. Retrieved from http://mktsci.journal.informs.org/content/25/4/384.abstract

Urban, G. L., P. L. Johnson, and J. R. Hauser (1984). Testing competitive market $\begin{array}{llll}\text { structures. } & \text { Marketing } & \text { Science, } & \text { 3(2), }\end{array}$ http://dx.doi.org/10.1287/mksc.3.2.83

Weitzman, M. L. (1979). Optimal search for the best alternative, Econometrica, 47(3), 641-654. http://dx.doi.org/10.2307/1910412 
